
у больных хронической обструктивной болезнью легких

\author{
Кафедра госпитальной терапии №1 ММА им. И.М.Сеченова, Москва
}

\author{
0.A.Tsevtkova, 0.0.Voronkova
}

\title{
System of pro-inflammatory cytokines in patients with chronic obstructive pulmonary disease
}

Хроническая обструктивная болезнь легких (ХОБЛ) является одной из ведущих проблем здравоохранения, в первую очередь из-за широкого распространения среди трудоспособного населения, постоянного, неуклонного прогрессирования, частого сочетания этой патологии с другими заболеваниями легких. Ведущим фактором риска возникновения заболевания на текущий момент признано курение. Оценку прогрессирования ХОБЛ необходимо проводить путем сравнения клинических показателей состояния пациента с показателями функции внешнего дыхания (ФВД) и с биомаркерами воспаления - как специфическими, так и неспецифическими, т. к. прогрессирование заболевания у данной группы больных обусловлено особенностиями процессов ремоделирования стенок бронхов. Для оценки возможности медикаментозной терапии влиять на замедление степени прогрессирования заболевания важно изучить динамику уровня провоспалительных цитокинов.

Обострение ХОБЛ чаще всего связано с респираторной вирусной инфекцией, которая клинически приводит к прогрессированию одышки, а функционально сопровождается снижением скоростных показателей функции дыхания.

На сегодняшний день известно, что полем воспаления при ХОБЛ являются мелкие бронхи, бронхиолы и ацинусы, где в результате воспаления слизистой и подслизистого окружения развивается гипертрофия гладких мышц этих структур, утолщение стенок бронхиол и вовлечение в процесс воспаления микроокружения бронхиол, что потенцирует развитие порочного круга воспаления, разрушение межальвеолярных мембран. Способствует персистированию воспаления привлечение к месту первичного повреждения фагоцитарно активных клеток - нейтрофилов, макрофагов, иммунокомпетентных клеток, являющихся основными источниками медиаторов воспаления. Баланс системы провоспалительных цитокинов и противовоспалительных цитокинов, факторов роста, регулирующих их выработку и взаимодействие, а также привлекающих к месту воспаления новые иммунокомпетентные клетки, определяет степень перехода обратимой обструкции дыхательных путей в необратимую обструкцию, и, следовательно, определяет тяжесть течения ХОБЛ.

Цитокины - это гормоноподобные белки, вырабатываемые различными клетками (лимфоцитами, моноитами, гранулоцитами, мастоцитами, эндотелиоцитами, фибробластами и другими клетками), обладающие широким спектром биологической активности, осуществляющие межклеточные взаимодействия при гемопоэзе, иммунном и воспалительном ответах, межсистемных взаимодействиях.

Цитокины традиционно делят на интерлейкины (IL-1- IL-15), факторы некроза опухоли (TNF- $\alpha$ и $\beta)$, фактор, ингибирующий миграцию, интерфероны, хемотаксические факторы, ростовые факторы (фактор роста фибробластов, трансформирующий фактор роста - ТФР- $\beta$, эпителиальные и эндотелиальные факторы роста и т. д.).

По основной направленности действия цитокины делят на провоспалительные (IL-1, IL-6, IL-8, IL-12, TNF- $\alpha$, ИНФ- $\alpha$, ФИМ), противовоспалительные (IL-4, IL-10, IL-13, TФР) и регулирующие иммунный ответ.

Цитокины принято делить по источнику их образования на лимфокины и монокины, однако это подразделение условно, поскольку один и тот же цитокин может синтезироваться клетками нескольких типов.

CD95 (APO-1, Fas-1) - один из специфических поверхностных рецепторов гибели клетки. Экспрессия CD95 (APO-1, Fas-1) на мембране клеток индуцируется рядом провоспалительных цитокинов, таких как IL-1, IL-2, IL-6, интерферонами, TNF- $\alpha$ и т. д. А также цитокины стимулируют увеличение молекул Fas-лиганда на лимфоцитах. Рецепторы "гибели" CD95 существуют в мембраноассоциированной и растворимой формах.

Лиганды CD95 (CD95L, FasL, Apo-1L) экспрессируются в большом количестве активированными Т-клетками, таким образом, одни и те же клетки, которые продуцируют факторы жизни клеток, могут также продуцировать факторы их гибели. CD 95L / CD 95 - молекулярные взаимодействия могут служить 
для ограничения экспансии иммунокомпетентных клеток независимо от гемопоэза в местах воспаления.

Ведущая роль в развитии патогенеза воспаления при ХОБЛ отведена нейтрофилам.

Как показывают уже существующие данные, крайне важно соблюдение баланса в регуляции апоптоза нейтрофилов между провоспалительными и противовоспалительными цитокинами, который обеспечивает своевременное устранение "излишних" гранулоцитов после исполнения их функции в очаге воспаления. Если же происходит торможение апоптоза нейтрофилов, то появляется риск развития персистенции воспаления окружающих тканей, т. к. нейтрофилы крайне агрессивно вырабатывают цитокины воспаления, что наблюдается у больных с гнойно-септическими заболеваниями при исследованиях различных маркеров апоптоза в бронхо-альвеолярном лаваже, при биопсии в слизистой бронхов и в крови.

Нейтрофилы и макрофаги - это доминирующие клетки, обнаруживаемые у больных ХОБЛ, в тканях бронхов и паренхимы легких, бронхоальвеолярном лаваже и мокроте. Хотя эти клетки играют важную роль в противомикробной защите, они также могут оказывать значительное воздействие, повреждая стенки бронхов и приводя к ремоделированию посредством секреции протеаз.

Непосредственное влияние на функции моноцитов/макрофагов оказывают различные цитокины посредством стимулирования или ингибирования активности клеток. Среди основных механизмов действия цитокинов следует отметить активацию генов синтеза собственно цитокинов и их рецепторов, продукцию хемотаксический факторов и молекул адгезии (хемокины, интегрины, селектины), экспрессию поверхностных маркеров, обеспечение цитотоксичности (противоопухолевой, противовирусной, антипаразитарной и антибактериальной), активацию молекул главного комплекса гистосовместимости для представления антигена цитотоксическим лимфоцитам. Необходимо учитывать при рассмотрении механизмов воспаления наличие аутокринной и паракринной регуляции функции макрофагов, поскольку большинство цитокинов как продуцируются собственно макрофагами, так и оказывают на них влияние, и к тому же возможен синтез подобных цитокинов другими клетками, но влияние они будут оказывать в первую очередь на макрофаги / моноциты. Еще одно важное свойство цитокинов - это плейотропность и полифункциональность - одни и те же цитокины могут выполнять разные функции и оказывать влияние на множество других различных клеток. Такие свойства цитокинов обусловлены высокой степенью гомологии в строении разных цитокинов, использование при активации одних и тех же рецепторов или рецепторных субъединиц, использование одинаковых каналов передачи в клетку стимула, различием во вре- мени между акитвацией генов цитокинов и их процессингом [1].

Запрограммированная клеточная гибель - естественный процесс, который находится под контролем генетической регуляции. Нейтрофилы имеют самый высокий индекс чувствительности к апоптозу (Bax / Bcl-2), по сравнению с другими иммунокомпетентными клетками, что объясняет их короткий жизненный цикл. При этом нейтрофилы обладают высоким агрессивным потенциалом, направленным в первую очередь на уничтожение бактерий, вирусов, грибов, иммунных комплексов, неопластических клеток, который, однако, в условиях патологии может становиться значимым повреждающим фактором. Апоптоз ограничивает токсический потенциал нейтрофилов, способствуя завершению острого воспалительного процесса.

В развитии и функционировании нейтрофилов можно выделить 3 стадии, когда наблюдаются наиболее существенные различия по готовности клеток к реализации процесса апоптоза: 1) созревание в костном мозге; 2) пребывание в циркуляции; 3) нахождение в тканях, в т. ч. сюда необходимо отнести и экссудативные нейтрофилы (саливарные, перитонеальные, раневые, интраназальные, вагинальные, бронхоальвеолярные) [2].

Установлено, что нейтрофилы костного мозга менее подвержены спонтанному апоптозу in vitro, чем циркулирующие нейтрофилы. При исследовании процесса созревания нейтрофилов в костном мозге было обнаружено, что вовремя конечной дифференцировки в зрелые нейтрофилы в клетках значительно уменьшается количество антиапоптических протеинов Bc1-2 и Bcl-xl и окончательно прекращается экспрессия их мРНК, тогда как уровень проапоптического гомолога Вс1-2-Вах сохраняется. Исчезновение антиапоптических гомологов объясняет раннюю смерть зрелых НГ, которые имеют самый высокий индекс чувствительности к апоптозу (Bax / Bcl-2), по сравнению с другими лейкоцитами [3].

Апоптоз нейтрофилов ускоряется взаимодействием Fas-рецептора (Fas / APO-1 / CD95) с Fas-лигандом (FasL), которые непосредственно связаны с индукцией апоптоза в различных клетках [4].

При исследовании нейтрофилов у больных с тяжелыми гнойно-септическими заболеваниями обнаружен интересный факт - наличие высокого процента нейтрофилов (по сравнению со здоровыми людьми) с выраженной экспрессией CD 95 (АРО-1, Fas) на мембранах клеток, что означало высокую готовность клеток к реализации апоптоза. Однако при этом обнаружено торможение гибели нейтрофилов по времени (по сравнению с нейтрофилами, CD95экспрессированными у здоровых людей), что означает наличие несостоятельности иммунитета у больных с тяжелыми гнойно-септическими заболеваниями в связи с дисбалансом между проапоптическими и антиапоптическими цитокинами [5]. 
Установлено, что, помимо индукции апоптоза, растворимый FasL стимулирует хемотаксис нейтрофилов без усиления секреторной активности. Эти факты указывают на новую роль FasL и подвергают сомнению устоявшийся постулат о том, что апоптоз не вызывает воспаления.

Функции Fas-антигена в норме и при патологических процессах в настоящее время являются предметом исследований.

Также важно оценить влияние лекарственной терапии на дисбаланс проапоптических и антиапоптических механизмов [6].

Например, давно известно, что при бронхиальной астме основной лечебный эффект глюкокортикоидов заключается в ускорении апоптоза таких гранулоцитов как эозинофилы и тучные клетки. Однако обнаружено обратное влияние глюкокортикоидов на нейтрофилы - замедление процессов апоптоза. Это вероятно, может объяснять не всегда достаточный эффект при лечении глюкокортикоидами тяжелых форм ХОБЛ, что требует дополнительного исследования [7].

Тонкость баланса проапоптических и антиапоптических механизмов также подтверждает факт обнаружения противоположных влияний TNF- $\alpha$ на нейтрофилы: с одной стороны, индукция апоптоза через стимуляцию рецепторов гибели на нейтрофилах (TNF R1 - "домен смерти" (p55), TNF R2 (p75); CD95(APO-1, Fas)); а с другой - торможение развития апоптоза через сфингомиелиновый сигнальный путь с экспрессией транскрипционного ядерного фактора кB (NF-kB), регулирующего продукцию антиапоптических белков $[5,6]$.

Наряду с проапоптическим эффектом, TNF- $\alpha$ обладает антиапоптическим действием на нейтрофилы. Например, инкубация нейтрофилов с TNF- $\alpha$ приводит к снижению их жизнеспособности в ранний период (2-6 ч). Однако добавление TNF- $\alpha$ к нейтрофилам, культивировавшимся до этого более 6 ч, не вызывает ускорения апоптоза, а длительная совместная инкубация (12-24 ч) оказывает антиапоптическое действие.

Большинство нейтрофилов самостоятельно экспрессируют Fas и FasL и являются наиболее чувствительными среди фагоцитов к быстрому апоптозу in vitro после связывания Fas c FasL или моноклональными антителами (MKAT) анти-Fas. Fas-индуцированный апоптоз нейтрофилов супрессируется глюкокортикоидами, колониестимулирующими факторами (Г-КСФ, ГМ-КСФ), интерфероном- $\gamma$ (ИФН- $\gamma)$, TNF- $\alpha$, бактериальным липополисахаридом (ЛПС) [8].

ГМ-КСФ (гранулоцитарно-моноцитарный - колониестимулирующий фактор) ингибирует TNF- $\alpha-$ индуцированную активацию каспаз и, соответственно, препятствует развитию апоптоза. ГМ-КСФ

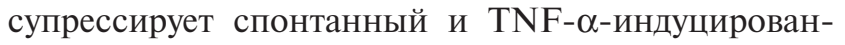
ный апоптоз нейтрофилов. Антиапоптическое действие ГМ-КСФ не ослабляется с возрастом (в отли- чие от IL-2 и ЛПС). Предварительная обработка нейтрофилов ГМ-КСФ защищает их от ускоренного апоптоза, вызванного ультрафиолетовым (УФ) облучением. Кроме протективного действия, ГМ-КСФ способен остановить развитие апоптических изменений в нейтрофилах и вернуть их к нормальному функционированию, будучи добавленным спустя 90 мин после УФ-экспозиции.

Г-КСФ (гранулоцитарный колониестимулирующий фактор), ингибируя спонтанный апоптоз зрелых нейтрофилов, одновременно поддерживает их высокую функциональную активность: усиливает хемотаксис, мобилизацию цитозольного кальция, стимулирует фагоцитоз и бактерицидные функции.

Несколько различаются эффекты Г-КСФ и ГМ-КСФ на Fas-индуцированный апоптоз. ГМ-КСФ обладает более выраженным ингибирующим эффектом на Fas-индуцированный апоптоз, чем Г-КСФ, при этом нейтрофилы сохраняют свою функциональную активность. В присутствии же Г-КСФ функции нейтрофилов супрессируются пропорционально степени Fas-апоптоза [9].

IL-8 способен ингибировать спонтанный, Fas- и

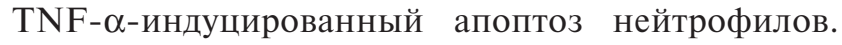
Влияние IL-8 на спонтанный апоптоз in vitro дозозависимо: при низких концентрациях (1-50 пг / мл) супрессирует, при высоких (100-5 000 пг / мл) - не обладает значительным эффектом. Ингибирование Fas-индуцированного апоптоза IL-8 осуществляет через супрессию связывания Fas c FasL.

Показано супрессирующее влияние IL-4 на апоптоз промиелоидных клеток, позволяющее им впоследствии дифференцироваться в нейтрофилы. IL-4 способен также дозозависимо ингибировать апоптоз зрелых нейтрофилов, одновременно активируя в них синтез de novo РНК, белков (актина) и стимулируя перестройку цитоскелета клетки.

IL-15 ингибирует апоптоз так же сильно, как и ГМ-КСФ.

IL-10, не влияя на спонтанный апоптоз нейтрофилов, отменяет антиапоптический эффект ЛПС, действуя как эндогенный ингибитор тирозинкиназ.

Гибель тимоцитов и некоторых других клеток организма под действием глюкокортикоидов является классической моделью апоптоза. Однако в нейтрофилах глюкокортикоиды подавляют апоптоз и поддерживают жизнеспообность клеток до 4 суток. Эффекты глюкокортикоидов специфичны и опосредуются через глюкокортикоидные рецепторы. Предполагают, что их действие основано на способности стимулировать синтез антиапоптических белков в нейтрофилах [7].

Известно, что уровень некоторых циркулирующих в крови цитокинов воспаления и острофазных белков у пациентов ХОБЛ выше нормы. Пока не исследовалось, как базисная терапия ХОБЛ влияет на их динамику. Задачей исследования O.Malo et al. [10] было описать изменения, происходящие в системе взаимодействия некоторых провоспалительных 
цитокинов, циркулирующих в крови, во время обострения заболевания у больных ХОБЛ и оценить потенциальный эффект проводимой кортикостероидной терапии. Для этого определяли уровень TNF- $\alpha$, IL-6 и IL-8 сыворотки крови и СРБ у 10 больных с ХОБЛ тяжелого течения в первые 24 ч госпитализации по поводу внезапно нараставшей дыхательной недостаточности, затем исследование крови проводили повторно при выписке больного и спустя 2 мес. А также была набрана контрольная группа из 8 здоровых человек того же возраста. В результате пациенты с диагнозом ХОБЛ имели значительно выше показатели уровня сывороточного IL-6, по сравнению с группой контроля, и при этом значения концентрации уровня IL-8 в сыворотке крови здоровой группы контроля и у больных ХОБЛ были похожими. Не было статистически значимого изменения ни во время улучшения, несмотря на кортикостероидную терапию, ни спустя 2 мес. Таким образом, полученные результаты продемонстрировали, что, вопервых, имеется доказательство наличия системного воспаления во время обострения ХОБЛ, а во-вторых, такое системное воспаление практически значимо не изменилось даже под действием в/в кортикостероидной терапии.

Интересно исследование, проведенное группой испанских ученых (M.Miravitlles et al.) [11], целью которого было определение роли повышенного уровня сывороточного IL-6 или его растворимого рецептоpa (sRIl-6) в активации системы воспаления у больных с дефицитом $\alpha-1$-антитрипсином. Обследованы 7 человек с дефицитом $\alpha-1$-антитрипсина и 23 человека с диагнозом ХОБЛ, но с таким же объемом обструкции по данным ФВД (ОФВ $135,5-38,3 \%)$ и примерно одного возраста (51-63 года), и сравнены показатели сывороточного IL-6 и его растворимого рецептора в этих 2 группах. Оказалось, что у больных с дефицитом $\alpha-1$-антитрипсина уровень IL-6 сыворотки в среднем составлял 4,7 pg / ml, при этом уровень растворимого рецептора IL-6 - в среднем 129,1 ng / ml, а у больных ХОБЛ с нормальным значением а-1-антитрипсина уровень IL-6 - 4,1 pg / ml, a sRIl-6 - 140,8 ng / ml в среднем. И только у одного больного с дефицитом а-1-антитрипсина уровень IL-6 был выше нормы. Таким образом, были обнаружены статистически не значимые различия значений уровня IL-6 и рецептора IL-6 сыворотки крови в обеих группах пациентов, что означает отсутствие разницы между этими показателями. Однако динамическое исследование этих цитокинов на фоне терапии не проводилось.

Повышение уровня IL-8 и онкогена- $\alpha$ регуляции роста (GRO-a), продуцируемых легочным эпителием, фибробластами и альвеолярными макрофагами, может быть спровоциоровано воздействием сигаретного дыма, эндотоксином или TNF-a [4]. Некоторые исследования in vivo и in vitro подтверждают значительную медиаторную роль IL-8 и онкогена- $a$ (GRO) посредством активации хемокинов (CXCR1 и
CXCR2) в индукции нейтрофильного хемотаксиса, эндотелиальной адгезии и дегрануляции [1].

Интересно исследование, проведенное A.Bhowmik et al., где обнаружена положительная корреляция между уровнями IL-6 и IL-8 в мокроте и частотой обострения ХОБЛ и стажем курения [12]. Причем повышение уровня и IL-6, и IL-8 в мокроте наблюдалось и в зависимости от стажа курения, и от факта наличия привычки курить на момент исследования, однако не наблюдалось положительной корреляции повышения уровня этих цитокинов в мокроте с показателями исходной функции легких, как было доказано в проведенных ранее исследованиях [13]. Известно, что IL-6 продуцируется бронхиальными макрофагами и, возможно, бронхиальным эпителием, IL-8 нейтрофилами и макрофагами. Однако в этом исследовании наблюдалось отсутствие повышения количества нейтрофилов и макрофагов в мокроте у больных с частым обострением ХОБЛ и при этом обнаруживалось повышение уровней IL-6 и IL-8 в мокроте, что еще раз подтверждает возможность продуцирования этих цитокинов эпителиальными клетками бронхов. Тем не менее исследователи не исключают также помимо факта курения и наличие бактериальной инфекции, которая, возможно, также играет роль в обострении ХОБЛ.

Потеря массы тела - это характерная черта прогрессирования ХОБЛ, связанного с более восприимчивым состоянием к обострению респираторных симптомов, и является независимым предиктором исхода заболевания. Потеря массы тела может происходить за счет различных тканевых компонентов, но потеря мышечной массы скелетной мускулатуры может быть особенно важной из-за страдания дыхательной мускулатуры с потерей ее силы и выносливости. Клинически не выявленная или практически асимптомная потеря массы скелетной мускулатуры может доходить до $25 \%$ у пациентов с нормальной массой тела.

Широко известно, что потеря массы - результат отрицательного энергетического баланса. Гиперметаболическое состояние (некатаболическое) рассматривается как основной механизм, который развивается из-за избытка энергетического расхода, вторично приводящему к повышению потребления кислорода при дыхании ("кислородная цена"), из-за механического препятствия - бронхиальной обструкции. Сниженное потребление энергии - возможно, еще один фактор, влияющий на потерю массы тела. Хотя исследования этого не подтверждают, энергетическое потребление может быть сниженным по метаболическим требованиям. Следовательно, маловероятно, что потеря массы тела при ХОБЛ - это простое снижение питания, адаптация к дефициту потребления энергии.

Легочное воспаление или тканевая гипоксия могут влиять на потерю общей массы тела как непосредственно через медиаторы воспаления, так и опосредованно - катаболически на метаболизм. Эту 
возможность подтверждает наличие различных медиаторов воспаления в бронхиальном секрете и наличие инфильтрации воспалительных клеток. Связь между воспалительным статусом и весом остается недоказанной, хотя TNF- $\alpha$ вовлечен как фактор потери веса.

Очень важно понимание механизма потери веса при ХОБЛ, потому что это связано с плохим прогнозом и потому что это является причиной кахексии при тяжелых неонкологических заболеваниях органов дыхания. Кроме того, механизмы, лежащие в основе этого явления, могут быть общими для других воспалительных заболеваний.

В исследовании A.Abdullah et al. была выдвинута гипотеза, что потеря мышечной массы может быть связана с доказанным воспалением, катаболическим ответом и тяжестью легочного заболевания. В исследовании определяли мышечную массу и ее взаимосвязь с легочной функцией, уровнем циркулирующих IL-6, TNF- $\alpha$ и их растворимыми рецепторами у пациентов с ХОБЛ [14]. Из 68 пациентов, у которых проводился анализ крови на маркеры воспаления, 29 человек имели дефицит мышечной массы и 39 человек имели нормальную мышечную массу. Значение уровня СРБ было одинаковым у обеих групп и со сниженной мышечной массой, и с нормальной мышечной массой и достоверно ниже, чем у здоровой группы людей. Концентрации IL-6, растворимого рецептора IL-6 и TNF- $\alpha$ и растворимого рецептора TNF- $\alpha$ (I и II типов) были достоверно выше в группе с дефицитом мышечной массы, по сравнению с группой с нормальной мышечной массой. У пациентов с нормальной массой тела и со снижением индекса мышечной массы имели достоверное повышение уровня IL-6, TNF- $\alpha$ и их рецепторов. Концентрации циркулирующих IL-6, TNF- $\alpha$ и их рецепторов у пациентов с нормальной массой тела и со снижением индекса мышечной массы и у пациентов со снижением и массы тела, и мышечной массы не имели достоверных различий.

Данные результаты подтверждают, что наблюдаемое снижение массы тела и мышечной массы связано с воспалительным ответом в организме. Это взаимоотношение было подтверждено обнаружением повышенной циркуляции уровня IL-6, TNF- $\alpha$ и их рецепторов у людей со снижением мышечной массы при нормальном значении индекса массы тела.

Большое значение имеет изучение динамики провоспалительных цитокинов на фоне традицион- ной базисной бронхолитической терапии, т. к. только в этом случае мы могли бы оценить возможность замедлить прогрессирование воспаления, что является одной из ведущих целей терапии.

\section{Литература}

1. Кетлинский С.А., Калинина Н.М. Цитокины мононуклеарных фагоцитов в регуляции реакции воспаления и иммунитета. Иммунология 1995; 3: 30-44.

2. Симбириев А.С. Цитокины: классификация и биологические функции. Цитокины и воспаление 2004; 3 (2): $16-22$.

3. Долгушин И.И., Бухарин О.В. Нейтрофилы и гомеостаз. Екатеринбург; 2001.

4. Туев А.В., Мишланов В.Ю. Клиническая оценка функции лейкоцитов у больных с синдромом бронхиальной обструкции. Астма 2001; 2 (1): 128-129.

5. Нестерова И.В., Швыдченко И.Н. Регуляция апоптоза в системе нейтрофильных гранулоцитов. Аллергол. и иммунол. 2001; 2 (1): 53-67.

6. Stockley R.A. Neutrophils and protease/antiprotease imbalance. Am. J. Respir. Crit. Care Med. 1999; 160: s49-s52.

7. de Boer W.I. Cytokines and therapy in COPD. Chest 2002; 121 (5): 431-436.

8. Hsieh S.C., Huang M.N., Tsai C.Y. et al. The expression of genes modulating programmed cell death in normal human polymorphonuclear neutrophils. Biochem. Biophys. Res. Commun. 1997; 233 (3): 700-706.

9. Барышников А.Ю., Шишкин Ю.В. Иммунологические проблемы апоптоза. М.: Эдиториал УРСС; 2002.

10. Malo O., Sauleda J., Busquets X. et al. Systemic inflammation during exacerbations of chronic obstructive pulmonary disease. Thorax 2000; 55: 114-120.

11. Miravitlles M., Campos F., de la Roza C. et al. Importance of serum interleukin-6 as a mediator of systemic inflammation in patients with alpha-1 antitrypsin deficiency. Am. J. Respir. Crit. Care Med. 2000; 161 (5): 1608-1613.

12. Bhowmik A., Seemungal T.A.R., Sapsford R.J., Wedzicha J.A. Relation of sputum inflammatory markers to symptoms and lung function changes in COPD exacerbations. Thorax 2000; 55: 114-120.

13. Keatings V.M., Collins P.D., Scott D.M. et al. Differences in interleukin-8 and tumour necrosis factor in induced sputum from patients with chronic obstructive pulmonary disease and asthma. Am. J. Respir. Crit. Care Med. 1996; 153: 530-534.

14. Eid A.A., Ionescu A.A., Nixon L.S. Am. J. Respir. Crit. Care Med.2001; 164 (8): 1414-1418.

Поступила 11.10.04 (с) Цветкова О.А., Воронкова О.О., 2005 удК 616.24-036.12-092 